\title{
Discussion on Warehousing Management Problems and Countermeasures of Shazhou Turbine Pump Factory of Hunan Province
}

\author{
Shijun Yuan \\ Hunan Modern Logistics College \\ Changsha, China
}

\begin{abstract}
Efficient and reasonable warehousing can help manufacturers speed up the flow of materials, reduce costs, and achieve effective production and management of resources to ensure smooth production. This paper analyzes the current situation of the warehousing business of Shazhou Turbine Pump Factory of Hunan Province, and further explores the specific reasons for the idle warehousing facilities. On this basis, this paper proposes improvement measures from the aspects of resources, personalized services, and personnel training.
\end{abstract}

\section{Keywords—warehousing facilities; idle state; inventory}

\section{INTRODUCTION}

Shazhou Turbine Pump Factory of Hunan Province is a key enterprise of the Ministry of Electrical and Mechanical Services, which integrates science, industry, trade, production, supply and marketing. It specializes in the operation of turbine pump, hydro-generator sets of equipment and accessories, water conservancy machinery, agricultural irrigation and drainage equipment, and water supply and drainage pipelines. At the same time, the enterprise is an enterprise that has passed the ISO9001 international quality management system certification, specializing in the development, production and installation of turbine pump and water turbine.

\section{CURRENT STATUS OF WAREHOUSING OF SHAZHOU TURBINE PUMP FACTORY OF HUNAN PROVINCE}

Shazhou Turbine Pump Factory of Hunan Province is mainly engaged in the research, development, production and installation of turbine pump and water turbine. In terms of warehousing of the enterprise, the supply of warehousing facilities exceeds demand, and there is a serious phenomenon of idle equipment.

\section{A. Insufficient Investigation and Analysis on the Warehouse Construction}

The warehouse was designed to automate for automation. It did not fully understand the actual application, did not research and analyze its necessity, and found that the actual use of automation in the actual use was very low and the utilization was very small. This has led to major decision- making issues in the design and planning of automated warehouses prior to construction. The enterprise is a enterprise that produces and sells one-stop services. How to achieve near-zero inventory is very important for the enterprise. Effective near-zero inventory can reduce the funds occupied by inventory, thus speeding up the turnover of funds, which can greatly improve the liquidity of enterprises, effectively avoid the risk of product backlog, reduce the cost of inventory management and improve the efficiency of management. However, the enterprise is still far from this requirement, and there is still a large inventory, which needs to balance the relationship to reduce the amount of inventory.

\section{B. Insufficient Understanding of Improving the Mechanization and Automation of Warehouse Operations}

In the enterprise, the promotion of mechanized operations is not in place. A considerable number of employees are reluctant to use the equipment because of lack of understanding, and the ideas still remain on the basis of manual work. They are not confident enough about the new automated warehouse. They worry that the workers will be unemployed after using the machine, and they have not placed the automated warehousing in an important position, thus voluntarily giving up the research and use of automated warehousing.

\section{The Warehouse Equipment and Management System Have Not Been Upgraded in Time, and Some Warehouses Are Idle}

Hunan's economy is developing rapidly. The external factors and situation of the enterprise are constantly changing and developing. However, the warehouse equipment and management system have not changed and upgraded. Over time, the enterprise has lost part of the original market, and the warehouse is in an idle state. At present, some of the enterprise's warehouse equipment is outdated; some warehouse equipment is not perfect; and it is necessary to add advanced equipment and eliminate some old equipment. The outdated equipment wastes time, reduces labor efficiency, and reduces the utilization of warehousing facilities. Many of the operations are still in the original state 
of manual work. The work efficiency is low; equipment is old; and the warehouse utilization rate is low. Many warehouses are in a state of "goods can't come in or go out". The goods stay in the warehouse for too long, or improper warehousing, damage, mildew and serious losses will increase the logistics cost. However, people's understanding of this is not deep.

\section{ANALYSIS OF WAREHOUSING MANAGEMENT PROBLEM OF THE ENTERPRISE}

\section{A. The Supply of Warehousing Facilities Exceeds Demand}

Shazhou Turbine Pump Factory is a key enterprise of the Ministry of Electrical and Mechanical Services, which integrates science, industry, trade, production, supply and marketing. It specializes in the operation of turbine pump, hydro-generator sets of equipment and accessories, water conservancy machinery, agricultural irrigation and drainage equipment, and water supply and drainage pipelines. Yongzhou Lengshuitan Turbine Pump Co., Ltd., its subsidiary enterprise, is located in the beautiful Phoenix Park of Yongzhou City. It is a joint-stock enterprise established on the basis of the original Yongzhou Hydropower Plant. It was founded in 1990 and is an enterprise that has passed the 1SO9001 international quality management system certification, specializing in the development, production and installation of turbine pump and water turbine. At present, the common situation of enterprises with warehouses and handling facilities is that ordinary single-storey house, simple warehouses and ordinary building houses are the main types of warehousing, and so is the enterprise. The aging problem of such warehousing facilities is the main reason for the oversupply of the enterprise's warehousing facilities. In addition, the enterprise's specific needs are another major obstacle. Therefore, the enterprise's warehousing capacity is a relative structural excess.

\section{B. The Warehouse Area Is Large, But the Layout Is Not Reasonable Enough}

The enterprise has more than 1,000 square meters of warehouses. However, due to the different demand number of customers, types of products and materials of products, as well as the lack of professional knowledge and management ability of warehouse managers, the warehousing layout is extremely unreasonable, which leads to the polarization of large amount of surplus in some warehouses and insufficient warehousing capacity in others. Especially in the face of some customers with small and single batch of products, the contradiction between idle and repeated configuration of warehouse facilities and equipment resources is prominent. Under this system, all departments of the enterprise build their own warehouses for their own interests and conveniences, forming a "production warehouse", "sales warehouse", "raw material warehouse", etc. The warehouse is used to meet the needs of each other and the situation of mutual closure and repeated construction still exists, and the warehousing industry is low in socialization. Due to this decentralized management system, the polarization of certain departments' warehousing capacity and the lack of warehousing capacity of certain departments are formed. This will inevitably result in decentralized funds, backward management, and low utilization of warehouses.

\section{Lack of Information Technology and High-tech Facility Operators}

The enterprise does not pay attention to the training of mechanical operators and maintenance personnel, leading to the lack of operation and maintenance personnel. Some of the existing equipment of the warehousing enterprises can't play their due role. The subsequent maintenance and development were not considered in the design of the new warehouse, which limited the use of equipment and the improvement of automation level. After installation, some systems fail and damage; accessories and after-sales service can't keep up with it, and maintenance is very difficult. Lack of talent can lead to unprofessional warehousing operations.

The lack of information technology and high-tech facility operators and professionals has left some of the enterprise's facilities in an unmanned or inoperable state, seriously affecting the development of the enterprise's warehousing.

\section{WAREHOUSING DEVELOPMENT COUNTERMEASURES} OF SHAZHOU TURBINE PUMP FACTORY OF HUNAN PROVINCE

\section{A. Finding a Balance Between Transportation Costs and Inventory Costs}

For many companies, the advantages of compressed inventory are obvious, such as reducing inventory funds, speeding up capital turnover, reducing inventory management costs, and avoiding the risk of price cuts and slow sales caused by market changes. However, many companies ignore the law that there is a antinomy between transportation costs and warehousing costs. When the inventory cost is reduced; the transportation cost will inevitably increase; and the two cannot be simultaneously reduced to the minimum. For the enterprise, it is not the cost compression of a certain aspect or link, but the optimization of the overall resources. It is wise to find a balance between transportation costs and inventory costs, rather than blindly compressing inventory.

\section{B. Making Adjustments on Specialized Personalized Services}

With the formation of the buyer's market, China's warehousing industry has gradually exposed its drawbacks. A large number of warehousing facilities can't meet the individual needs of the enterprise. For example, the enterprise's demand for three-dimensional warehousing is growing, but the current status of warehousing cannot meet this demand. Therefore, the enterprise's warehousing industry needs to make adjustments in specialized and personalized services, and make technical transformations and structural adjustments to the market to meet the market needs of enterprises. 


\section{Integrating Resources and Continuously Improving the} Operational Efficiency of Warehousing

1) Strengthening the construction of warehousing infrastructure: It is necessary to increase investment, strive to upgrade the infrastructure of existing warehouses, continuously transform old and aging warehouses, and update and use the modern warehousing equipment. It is necessary to learn from the advanced experience and technology in China and foreign countries, and to combine the actual conditions of each region, and to develop a scientific and rational network of warehousing facilities.

2) Strengthening the integration of warehousing resources and improving the warehousing standardization system: Warehousing standardization is not only to achieve close cooperation between the warehousing and other links, but also an effective means to improve the efficiency of operations within the warehousing. Therefore, warehousing companies must constantly improve their standardization system.

3) Accelerating the construction of public information platforms and realizing the information management of warehousing: To improve warehouse utilization and achieve effective inventory control, it is necessary to establish an effective information network, realize warehousing information sharing, and actively promote warehousing management informationization of the enterprise. It is convenient to use modern information technology to build a public information platform, realize the effective combination of public information network and warehousing network, and improve the level of enterprise warehousing information.

\section{Changing Concepts and Introducing Technology and Talents}

1) Grasping the focus of skill-based talent training: Warehousing enterprises should combine new business development and new technology applications, focusing on training of employees in computer software applications, special materials pledge business, distribution business, and professional machinery application technology. Professional training and compound talent training should be combined in the training process. The current business needs to be combined with the business needs to be developed; the traditional skills training is combined with the modern new technology learning; the school theoretical knowledge is combined with the application training, the inter-enterprise learning exchange and the mentoring skills. It is convenient to incorporate the practical application of computer software, use existing business processes, and standardize operational requirements to implement integrated strategic training. At the same time, it should reflect the training characteristics of the industry, not only pay attention to the cultivation of business skills, but also strengthen the training of corporate culture and professional ethics.
2) Targeted introduction of skilled talents: The competition in the logistics market is fierce. Especially after China's accession to the WTO, as foreign-funded enterprises are increasingly landing in the Chinese market, the competition for skilled talents is intensifying. In response to this situation, domestic warehousing enterprises should first take the initiative to formulate corresponding talent introduction strategies. For the skilled talents that are urgently needed for enterprise production, the enterprises should actively introduce them through the social labor market. At the same time, the enterprises should vigorously adopt the means and mechanisms for retaining talents and effectively avoid brain drain. Also, the enterprises should strive to do the work of receiving college graduates.

3) Strengthening the cultivation of professional talents: There is no doubt that the competition among today's enterprises ultimately comes down to the competition of talents. Since warehousing management is a relatively operationally strong industry, it is only possible to design and manage the entire process, and to realize the integration and specialization of services, only if the actual on-site operations are well known. Therefore, cultivating and absorbing a combination of technical, mechanical, and management-type composite managers is a top priority.

\section{CONCLUSION}

Warehouse is a comprehensive place that reflects the status of enterprise logistics activities. Warehouse management is an important part of material management. Warehouse is an important condition for balancing market supply and demand and stabilizing prices. It is a transfer station that connects production, supply and sales. Therefore, warehousing is a very important process of logistics. It is convenient to continuously improve the operational efficiency of warehousing from the warehouse layout optimization, personnel introduction and training, integration of resources, and the improvement of the mechanization and automation level of warehouse operations.

\section{REFERENCES}

[1] Ren Hongying, He Guimin. Research on optimization of warehouse management system [J]. Manager's Journal. 2015(06). (in Chinese)

[2] Li Zhengzhong, Liu Jiabin, Li Tao. Current status and optimization strategy of power material warehousing management $[\mathrm{J}]$. China Warehousing and Transportation. 2011(12). (in Chinese)

[3] Liu Quangeng. Research on warehouse management problems of $x$ warehouse and countermeasures [D]. Henan University of Science and Technology, 2015. (in Chinese) 